\title{
Consequences of Early Experiences and Exposure to Oxytocin and Vasopressin Are Sexually Dimorphic
}

\author{
C. Sue Carter ${ }^{\mathrm{a}}$ Ericka M. Boone ${ }^{\mathrm{a}, \mathrm{c}}$ Hossein Pournajafi-Nazarloo ${ }^{\mathrm{a}}$ \\ Karen L. Bales ${ }^{b}$ \\ a Department of Psychiatry, Brain Body Center, University of Illinois at Chicago, Chicago, Ill., b Department of \\ Psychology, University of California, Davis, Calif., and 'National Institute on Drug Abuse, NIH, DHHS, \\ Bethesda, Md., USA
}

\section{Key Words}

Oxytocin · Vasopressin · Pitocin · Sex differences · Early experience $\cdot$ Prairie voles

\begin{abstract}
In the socially monogamous prairie vole, we have observed that small changes in early handling, as well as early hormonal manipulations can have long-lasting and sexually dimorphic effects on behavior. These changes may be mediated in part by changes in parental interactions with their young, acting on systems that rely on oxytocin (OT) and arginine vasopressin (AVP). Knowledge of both endogenous and exogenous influences on systems that rely on OT and AVP may be helpful in understanding sexually dimorphic developmental disorders, such as autism, that are characterized by increased anxiety and deficits in social behavior.
\end{abstract}

Copyright $\odot 2009$ S. Karger AG, Basel

Experiences in early life, especially when the nervous system is developing, can have long-lasting behavioral consequences. In the postnatal period, parental interactions with the offspring engage behavioral and emotion- al systems allowing young animals to adjust to their immediate environment and also prepare for future social and physical challenges. Oxytocin (OT) and arginine vasopressin (AVP) are mammalian neuropeptides that have been implicated in the development and expression of social behavior and emotion regulation. In this context OT and AVP are excellent candidates as mediators of the effects of early experience. The approaches used here include examining the behavioral and neuroendocrine effects of early manipulations of the family and also developmental manipulations of OT, using peptide agonists and antagonists. In addition, we will survey new findings regarding the consequences of differential early experiences on OT or AVP, or behavioral and emotional systems that are affected by those peptides.

Studies drawn from recent research using a socially monogamous rodent, the prairie vole, will be the focus of this review. Prairie voles share with humans the capacity to form pair bonds and may exhibit alloparental and biparental behavior. This species has been especially useful in understanding several functions of OT and AVP [Carter et al., 1995; Carter, 2007; Lim et al., 2004a]. We also present data supporting the hypothesis that changes in OT and AVP are components of an endogenous system

\section{KARGER \\ Fax +4161306 1234 \\ E-Mail karger@karger.ch}

www.karger.com
(C) 2009 S. Karger AG, Basel

Accessible online at:

www.karger.com/dne
Sue Carter

Department of Psychiatry, Brain Body Center

University of Illinois at Chicago

Chicago, IL 60612 (USA)

Tel. +1 312355 1593, Fax +1 312996 7658, E-Mail scarter@psych.uic.edu 
that developmentally programs individual behavioral patterns to accommodate changes in the environment.

\section{Early Experience, Natural History and the Family}

The effects of early experience on later behavior may be best interpreted in the context of the natural history and social organization of a given species. Under field conditions prairie voles may form pair bonds. Over time, family groups form around these pairs including older siblings, who often remain with the natal family as alloparents. Up to $70 \%$ of young animals do not form new families, living instead as part of communal breeding groups [Getz and Carter, 1996]. Differential family composition may produce differences in the amount of stimulation received by offspring. Females, through loss of a mate, may be single parents and older offspring may serve as 'helpers at the nest'. It is likely that early experience, mediated in part by changes in peptidergic systems, could be a factor in determining whether a given animal becomes either a member of a pair bond or an alloparental member of a communal breeding group. In nature females are rarely found alone, although males may live in solitary nests. Sexually dimorphic constraints on reproduction may help to explain sex differences in the consequences of early experiences including developmental reactions to neuropeptides.

As detailed below, we have found that early hormonal experiences can alter the expression of AVP V1a receptors (V1aR). In nature or under seminatural conditions variation in the $\mathrm{VlaR}$ exceeds that observed in the laboratory, supporting the notion that the AVP system may have an important role in subsequent social behavior and reproductive success [Ophir et al., 2008; Phelps and Young, 2003].

\section{Environmental Programming of Social, Emotional and Endocrine Systems}

The consequences of early experiences may be mediated both by endocrine changes originating in the organism itself (including the developmental secretion of steroids or peptides), as well as through parental influences, including the epigenetic effects of postnatal parental stimulation. In turn, endocrine events, turned by early experience, may regulate the endocrine system of the developing neonate, with long-lasting consequences for emotion, behavior and physiology. Early experience can be mediated by several aspects of the parent-infant interaction.

Exogenous synthetic OT (pitocin) is widely used to induce or augment labor. It has been sometimes assumed that pitocin given to the mother does not pass through the placenta in amounts sufficient to affect the baby. However, this assumption is not well studied and the placental barrier can be disrupted during birth or by other stressors. In addition, treatments of pregnant women, such as atosiban, an OT antagonist (OTA) used to delay labor, may have the potential to affect the offspring's development. Maternal exposure to pitocin can alter the strength or duration of uterine contractions, resulting in differential fetal exposure to hypoxia. Pitocin, especially in conjunction with a surgical birth or anesthesia, also may influence the subsequent ability of the mother to lactate or interact with her offspring in the immediate postpartum period.

Compounds of maternal origin may be transmitted to the infant, either during the prenatal or postnatal period. Treatments in the prenatal period may alter the duration of pregnancy, the intensity of labor, and postnatal parentinfant interactions, with possible direct or indirect effects on the offspring. In addition, in the postnatal period maternal milk contains biologically active compounds, including prolactin [Grosvenor et al., 1993], cortisol [Glynn et al., 2007], and OT [Leake et al., 1981].

\section{Oxytocin and Vasopressin: Background and Sex Differences}

OT and AVP are composed of a six amino acid ring, with a three amino acid tail; these peptides differ from each other by two of nine amino acids. OT and AVP are synthesized primarily in the central nervous system. OT is best known for its role in birth and lactation. AVP is classically associated with cardiovascular functions, including blood pressure, and water balance through effects on the kidney. However, both OT and AVP also have roles in mammalian sociality, including parental behaviors [Bales et al., 2004] and social bonding [Cho et al., 1999]. In addition, both OT and AVP also regulate the hypothalamic-pituitary-adrenal (HPA) axis and the autonomic nervous system, although the effects of OT versus AVP on autonomic functions probably differ in direction [Vivani and Stoop, 2008].

Both OT and AVP are found in high concentrations in the paraventricular (PVN) and the supraoptic nuclei (SON) of the hypothalamus. From their sites of synthesis 
in the PVN and SON, these peptides are carried by axonal transport to the posterior pituitary, where they are released into the bloodstream. AVP is also present in several other areas including the medial amygdala (MeAmy), bed nucleus of the stria terminalis (BNST) and lateral septum (LS) [De Vries and Simerly, 2002]. OT and AVP are released into the central nervous system and may act on receptors in several target areas, presumably through effects on their own receptors and in some cases crossreacting with each other's receptors [Landgraf and Neumann, 2004].

Only one OT receptor (OTR) has been described. The same OTR is present in neural tissue and in other parts of the body including the uterus [Gimpl and Fahrenholz, 2001]. Three receptor subtypes have been identified for AVP. Of these, the V1aR, which is found in the brain, has been associated with paternal behavior [Bales et al., 2007b; Bester-Meredith and Marler, 2003] and social behaviors including social engagement and pair bond formation, especially in males [Winslow et al., 1993]. The V1b receptor has been implicated in endocrine and behavioral responses to stressors and aggression, and may play a particularly important role in behaviors that rely on olfaction or olfactory memory [Caldwell et al., 2008]. The V2 receptor is localized to the kidney and does not appear to be involved in behavior.

Receptors for both OT and AVP are localized in areas of the nervous system that regulate social and adaptive behaviors, the hypothalamic pituitary adrenal (HPA) axis, and the autonomic nervous system. Both individual and species differences in VlaR receptor distributions have been identified. Among the sources of these differences are species-typical variations in the promoter region of the VIaR gene [Hammock and Young, 2005]. The OTR also shows species differences in expression [Insel and Shapiro, 1992; Witt et al., 1991]. Sex steroids can influence OT and the OTR [Gimpl and Fahrholz, 2001]. Furthermore, the effects of steroids on the OT-OTR system are species specific and complicated by the many interactions among steroids and their receptors. For example, estrogen receptors have several forms, including an $E R \alpha$ and ER $\beta$, which in turn may respond to different ligands with different functions [Choleris et al., 2008; Weiser et al., 2008].

Synthesis of AVP within the central nervous system is sexually dimorphic, and influenced by developmental exposure to androgens [De Vries and Simerly, 2002]. Specifically, cells that synthesize AVP in the MeAmy and BNST and fibers from these cells that extend into the LS are more abundant in males than females. In addition, males seem more responsive than females to AVP [Winslow et al., 1993].

Recent studies in humans implicate OT and AVP in the response to stressors, repetitive behaviors and anxiety [Carter, 2007]. OT may reduce anxiety and reactivity to stressors, as well as repetitive behaviors. Research in animals also suggests major roles for OT in maternal behaviors, sexual behavior, social recognition, social contact, and facilitate pair bonding. AVP, working in conjunction with OT, may be of particular relevance to male social behaviors including paternal behavior, pair bond formation and the selective aggression that is involved in mate defense. The effects of AVP are probably not linear. In prairie voles, either reduced access to the V1aR or exposure to higher endogenous AVP may be anxiogenic [Carter, 2003].

Sex differences in the AVP system could have broad consequences for behavior and physiology, forming an underlying substrate for several behavioral processes that are typically attributed to androgens. It is possible that in males both peptide synthesis and receptor functions are primed by early exposure to androgens, including exposure in the early postpartum period [De Vries and Simerly, 2002]. Sex differences in central AVP may be involved in the capacity of OT manipulations in early life to have differential long-term effects in males and females. However, in comparison to OT, the possible behavioral functions of AVP in females have received less attention, so these conclusions must remain tentative.

OT and AVP have some overlapping functions, possibly because they can bind to each other's receptors. However, under other conditions, and especially with regard to behavioral arousal and mobilization, the behavioral effects of OT and AVP seem to be opposing [Carter, 1998]. For example, exogenous OT and AVP can both facilitate pair bonding in prairie voles [Cho et al., 1999] and both may be involved in male parental behavior [Bales et al., 2004]. In females OT facilitates birth, lactation and lordosis, each of which requires immobilization, at least for a period of time. In general, exogenous OT's effects are associated with an enhanced capacity for immobility [Porges, 1998] and OT may regulate the reactivity of the HPA axis. AVP is more often associated with mobility, and various adaptive, defensive behaviors. AVP may increase arousal and has the capacity to synergize with corticotropin-releasing factor (CRF) as a secretagogue for ACTH [Engelmann et al., 2004]. Active coping and overt defensive behaviors may rely on AVP, while OT is important to behaviors that are characterized by immobility and passive coping strategies. 
Table 1. Differential early handling experiences on postnatal day 1 can alter subsequent indices of anxiety, alloparenting and pairbonding in prairie voles

\begin{tabular}{|c|c|c|c|c|c|c|}
\hline Neonatal TRMT & $\begin{array}{l}\text { MAN1 } \\
\text { male }\end{array}$ & $\begin{array}{l}\text { MAN1 } \\
\text { female }\end{array}$ & $\begin{array}{l}\text { MAN0 } \\
\text { male }\end{array}$ & $\begin{array}{l}\text { MAN0 } \\
\text { female }\end{array}$ & $\begin{array}{l}\text { MAN1 }(\times 3) \\
\text { male }\end{array}$ & $\begin{array}{l}\text { MAN1 }(\times 3) \\
\text { female }\end{array}$ \\
\hline Anxiety (EPM) & comp. low & comp. low-moderate & $\uparrow$ & $\uparrow$ & $\uparrow$ & $\mathrm{NC}$ \\
\hline Alloparental behavior & comp. high & low-moderate & $\downarrow$ & NC & $\downarrow$ & NC \\
\hline Pair-bond formation & comp. high & comp. high & $\mathrm{NC}$ & $\downarrow$ & NA & NA \\
\hline Parental behavior (own pups) & normal & normal & $\downarrow^{*}$ & $\downarrow^{*}$ & NA & NA \\
\hline OT-ir, PVN & normal & normal & $\mathrm{NC}$ & $\mathrm{NC}$ & $\downarrow$ & $\mathrm{NC}$ \\
\hline OT-ir, SON & normal & normal & $\downarrow$ & $\downarrow$ & $\downarrow$ & $\mathrm{NC}$ \\
\hline OT plasma & normal & normal & $\mathrm{NC}$ & $\downarrow$ & $\mathrm{NC}$ & $\uparrow^{1}$ \\
\hline AVP plasma & normal & normal & $\mathrm{NC}$ & $\uparrow^{1}$ & $\mathrm{NC}$ & $\mathrm{NC}$ \\
\hline OTR & normal & normal & $\uparrow^{* *}$ & $\uparrow * * *$ & NA & NA \\
\hline AVP V1aR & normal & normal & $\mathrm{NC}$ & $\mathrm{NC}$ & NA & NA \\
\hline
\end{tabular}

MAN1 = Parents and young are picked up by the scruff of the neck during cage changes; MAN0 = parents and young are handled with a cup during preweaning changes; $\operatorname{MAN} 1(\times 3)=$ parents and young are picked up by the scruff three times on postnatal day 1. Directional arrows indicate changes in comparison to MAN1.

$\uparrow=$ Significant increase; $\downarrow=$ significant decrease. ${ }^{1}$ Trend to increase.
* Reductions in multiple measures of parenting towards own pups. ${ }^{* *}$ Increased OTR binding in bed nucleus of stria terminalis (BNST) and lateral septum (LS) compared to MAN1 males. *** Increased OTR binding in nucleus accumbens, BNST and LS compared to MAN1 females. $\mathrm{NC}=$ No significant changes; $\mathrm{NA}=$ data not available; OT-ir = oxytocin immunoreactivity; OTR = oxytocin receptor; AVP = arginine vasopressin; AVP V1aR = AVP $\mathrm{V}$ la receptor; $\mathrm{EPM}=$ elevated plus maze.

\section{Early Manipulations of the Family Can Have Lasting Effects on Behavior and Anatomy}

In prairie voles, behavioral manipulations, created by different methods of handling the parents or offspring in the postnatal period, had life-long consequences for behavior and physiology [Bales et al., 2007a] (table 1). In a series of experiments, we have examined the effects of differential neonatal behavioral treatments of infants and family on later behavioral and neuroendocrine responses. Compared to studies done in rats, which typically involve periods of separation from the mother, the actual handling or manipulations described here in voles were very subtle. During a regular cage change, usually within the first day of life, the parents and offspring were transferred to a fresh cage using a cup, either without direct 'handling' of the animals (MAN0) or by picking up the parents and offspring by the scruff of the neck for movement between cages on the first day of life (MAN1). These postnatal day 1 (PND1) manipulations were done either once (MAN1) or three times at 3-hour intervals [MAN1 $(\times 3)]$. Pups of this species have milk teeth and are typically attached to their mother. The father was also transferred to a new cage at the same time.

Early Experience, Peptides and Sex

Differences in Development
Observations during the postnatal period suggest that mild disruptions of the family, such as those experienced in the MAN1 treatment, were followed by increases in parental behavior, especially on the part of the mother but also by the father. Families transferred in a cup (MAN0) appeared less disturbed, but offspring from the MAN0 treatment did not show typical patterns of behavior. When male offspring from either the MAN0 or MAN1 $(\times 3)$ groups were tested for alloparental behavior following weaning they often failed to attend to the pups and in some cases attacked the pups. Female prairie voles are less likely to be spontaneously alloparental and females from these various rearing groups did not differ in alloparenting, although MAN0 females were less likely than MAN1 females to form pair bonds, even after extended periods of cohabitation with a partner [Bales et al., 2007a].

Neuroendocrine changes as a result of early experience may in part explain the behavioral effects of such manipulations. Males from both the MANO and MAN1 $(\times 3)$ groups that showed inhibitions in alloparenting also exhibited reductions in the number of SON cell bodies immunoreactive (ir) for OT. In males from the MAN $1(\times 3)$ group OT-ir was reduced in the PVN. In females behavioral differences in alloparenting were not detectable, possibly due to generally low levels of allopa- 
Table 2. Effects in later life of postnatal day 1 exposure to a single injection of OT (oxytocin, low dose $=3$ or $6 \mu$; high dose $=12$ or $24 \mu \mathrm{g}$ ), or OT antagonist (OTA, $0.3 \mathrm{ng}$ ) in prairie voles

\begin{tabular}{|c|c|c|c|c|c|}
\hline Neonatal treatment & OT (low dose), males & OT (low dose), females & OT (high dose), females & OTA, males & OTA, females \\
\hline Anxiety (EPM) & $\downarrow 3 \mu \mathrm{g}$ & NC & $\mathrm{NC}$ & $\mathrm{NC}$ & $\mathrm{NC}$ \\
\hline Alloparental behavior & $\uparrow 3 \mu \mathrm{g}$ & $\mathrm{NC}$ & $\uparrow^{1}$ & $\downarrow$ & $\mathrm{NC}$ \\
\hline Pair-bond formation & $\uparrow 3 \mu \mathrm{g}$ & $\uparrow 6 \mu \mathrm{g}$ & $\downarrow 12-24 \mu \mathrm{g}$ & $\mathrm{NC}$ & $\mathrm{NC}$ \\
\hline OT-ir, PVN & $\mathrm{NC}$ & $\uparrow 3 \mu \mathrm{g}$ & NA & $\mathrm{NC}$ & $\uparrow$ \\
\hline AVP-ir, PVN & $\mathrm{NC}$ & $\mathrm{NC}$ & NA & $\downarrow$ & \\
\hline OTR & $\mathrm{NC}$ & $\mathrm{NC}$ & NA & $\mathrm{NC}$ & $\mathrm{NC}$ \\
\hline AVP V1aR & $\uparrow^{*} 3 \mu \mathrm{g}$ & $\downarrow^{* *} 3 \mu \mathrm{g}$ & NA & $\downarrow * * *$ & $\downarrow * * * *$ \\
\hline
\end{tabular}

See table 1 for other abbreviations. In comparison to either saline or handled controls (which did not differ from each other).

$\uparrow=$ Significant increase; $\downarrow=$ significant decrease. ${ }^{1}$ Trend to increase.

In neonatal OT ( $3 \mu \mathrm{g})$ group males, ${ }^{*} \mathrm{AVP}$ V1a R was increased in the ventral pallidum and cingulate cortex ( $\mathrm{CgCtx})$, and in females, ${ }^{* *}$ reduced in the medial preoptic area (mPOA), bed nucleus of the stria terminalis (BNST), lateral septum (LS), CgCtx and medial thalamus. In the neonatal OTA $(0.3 \mu \mathrm{g})$ male group,
*** AVP VlaR was reduced in the mPOA, BNST and lateral septum, and in the female group, it was ${ }^{* * *}$ reduced in BNST and CgCtx.

Effects of higher doses of OT for males are available only for pair-bond formation. While a 3 - $\mu$ g dose facilitated pair-bonding in males [Bales and Carter, 2003b], males given a 6- $\mu \mathrm{g}$ dose showed no pair-bond, and a $12-\mu \mathrm{g}$ dose reinstated the bond [Carter et al., 2008]. renting in females. However, MAN0 females showed not only deficiencies in pair bonding, but also reductions in both hypothalamic OT-ir (SON), as well as reduced plasma OT. Consistent with this finding are earlier studies suggesting that female pair bonding is especially dependent on OT [Williams et al., 1994].

\section{Manipulations of Neonatal Peptides Also Have Long-Lasting Consequences}

We also have investigated in prairie voles the possible effects of direct manipulations of OT in early life (table 2). Within the first day of life males or females received injections of either OT or an OTA. Males again seemed especially sensitive to neonatal manipulations. A comparatively low dose of OT ( $3 \mu \mathrm{g})$ facilitated pair bond formation in males, possibly mediated in part by reductions in anxiety in these males. Neonatal OTA $(0.3 \mu \mathrm{g})$ treatment had opposite effects in males, inhibiting later alloparental behavior, although pair bonding was not affected.

The effects of administering either OT or OTA in males were correlated with changes in AVP and the V1a receptor, without measurable effects on endogenous OT or the OTR. In males OTA treatment was followed in later life by reductions in both AVP and VlaR binding. Conversely, a dose of OT that was associated with increased sociality also apparently increased VlaR binding in the ventral pallidum, which is a site for dopamine binding as well. A co-occurrence of the V1aR and dopamine has been implicated in male pair bond formation [Young et al., 2005] and may help to explain this outcome.

Although in females, the behavioral effects of a low ( $3 \mu \mathrm{g}$ ) dose of OT were minimal (affecting only 'mateguarding' [Bales and Carter, 2003a]), when females received a neonatal dose of $6 \mu \mathrm{g}$ of OT, pair bonding was facilitated. However, at a higher OT dose $(12 \mu \mathrm{g})$ pair bonding was no longer facilitated. In fact, in females that had received $24 \mu \mathrm{g}$ of OT, an atypical preference was shown for the unfamiliar males, possibly suggesting an avoidance of the familiar partners. Alloparenting was not inhibited by any of the neonatal OT treatments, and even at high doses females remained social. The dose of OTA that inhibited alloparenting in males did not have a significant behavioral effect in females; however, again because female alloparenting in untreated animals is comparatively low, negative effects of OTA would have been difficult to detect.

In female prairie voles, exposure to either OT or OTA was associated with an increase in hypothalamic (PVN) OT [Yamamoto et al., 2004]. Changes in receptor binding as a function of OT or OTA also were detected in V1aR binding. Neonatal OT exposure $(3 \mu \mathrm{g})$, although having no measurable effect on behavior, was associated with reductions in VlaR in the medial preoptic area, BNST, LS, cingulate cortex, and mediodorsal thalamus. OTA treat- 
ment was also associated with reductions in the BNST and cingulate cortex. It is possible that increases in endogenous OT synthesis associated with either neonatal OT or OTA in females were protective or compensated for the effects of blocking OTR. Alternatively, there is evidence from mice mutant for the V1aR that the absence of this receptor has little behavioral effect in females [Bielsky et al., 2005]. It is also possible that in general females are less behaviorally dependent on AVP, accounting for the relatively minor behavioral effects of OTA in female prairie voles.

\section{Can Oxytocin Exposure Reverse the Effects of Neonatal Manipulations?}

We have also conducted preliminary studies in males in which we attempted to remediate the deficits in alloparental behavior produced by neonatal exposure to OTA or the adverse effect of the MAN1( $\times 3)$. In both cases, a subsequent treatment on PND8 with OT (6 $\mu \mathrm{g})$ was associated with improvements in alloparenting [Boone et al., unpubl. data].

\section{Estrogen Receptors Are Also Affected by Neonatal Manipulations of OT}

Among the other long-lasting changes that followed neonatal manipulations of OT or OTA were effects on the later expression of estrogen receptors $(\mathrm{ER} \alpha)$ [Cushing and Kramer, 2005; Kramer et al., 2007]. In female prairie voles, neonatal OT increased the later expression of ER $\alpha$ in the ventromedial hypothalamus, while OTA decreased ER $\alpha$ in the medial preoptic area [Yamamoto et al., 2006].

A follow-up study indicated that during the neonatal period OT may affect the expression of ER $\alpha$ by influencing the production of ER $\alpha$ mRNA [Pournajafi-Nazarloo et al., 2007a]. On the day of birth female prairie vole pups were treated with OT, OTA or saline (as above). Within $2 \mathrm{~h}$ of treatment, OT significantly increased ER $\alpha$ mRNA expression in the hypothalamus and hippocampus, but not the cortex (measured by RT-PCR). In contrast, neonatal exposure to OTA was associated with a later reduction in the expression of ER $\alpha$ mRNA in the hippocampus. Neonatal treatment did not affect the expression of the ER $\alpha$ mRNA. Regionally specific changes in ER $\alpha$ mRNA expression in females are consistent with other studies examining the behavioral and physiological effects of neonatal manipulation of OT in females. Significant effects on ER $\alpha$ of neonatal OT manipulations were not detected initially in males [Cushing and Kramer, 2005]. However, in a subsequent study exposure to neonatal OTA was associated with an increase in ER $\alpha$ in the BNST [Kramer et al., 2007]. These studies again support the hypothesis that manipulations of OT can have organizational effects, and that the effects of OT are sexually dimorphic. In the case of ER $\alpha$, females tended to be more sensitive than males, at least to the effects of neonatal OT. $\mathrm{ER} \alpha$ s play a role in a variety of social and reproductive behaviors; alterations in ER $\alpha$ s would be expected to have broad consequences for many systems upon which steroid hormones act both during development and also in adulthood, and are possible mediators of at least some of the effects of neonatal manipulations of peptides.

\section{Effects on Peptide Receptors}

Brain tissues from animals exposed to comparatively low doses of neonatal OT $(3 \mu \mathrm{g})$ or OTA $(0.3 \mu \mathrm{g})$ were studied using autoradiography for possible changes in the OT receptor (OTR), AVP receptor (V1aR), as well as dopamine receptors (D1 or D2) [Bales et al., 2007b]. Effects on the OTR and dopamine receptors of neonatal OT or OTA manipulations were not statistically significant. However, manipulations of OT on PND1 were associated with a pattern of regional changes in the V1aR system. Sex differences in the distribution of V1aRs in untreated prairie voles were not observed, consistent with earlier reports in this species. However, neonatal manipulations of OT produced long-lasting, sexually dimorphic effects on V1aR levels. Particularly striking were increases in VlaR binding in the ventral pallidum in males. In contrast, OT-treated females showed decreases in V1aR binding in this region. Long-lasting increases in the V1aR in the ventral pallidum could help to explain the enhanced sociality of males receiving neonatal OT. Reduced V1aR binding in adulthood, following neonatal OTA, especially in males that may depend on AVP, might help to explain reductions in later social behavior in OTA exposed males [Carter, 2007].

\section{Neonatal AVP Treatments Can Also Affect Subsequent Social Behaviors}

Earlier studies in prairie voles have revealed that neonatal exposure to AVP (in this case, given as daily injections in the first week of life) were associated with a later dose-dependent increase in same sex aggression, espe- 
cially in males [Stribley and Carter, 1999]. In contrast, neonatal exposure to an AVP antagonist was associated in later life with very low levels of aggression. Other aspects of behavior including exploration in an elevated plus maze and partner preference formation were not significantly affected by either neonatal AVP or the AVP antagonist. The effects of neonatal AVP manipulations on V1aR binding have not yet been examined in voles. Moreover, because these studies involved repeated daily injections and handling, the effects of AVP cannot be compared directly to those of OT described here, in which treatments were typically given only once on the first day of life.

Early exposure to gonadal steroids facilitates the response of adult male prairie voles to exogenous AVP. In adult male prairie voles AVP plays a major role in pair bond formation [Winslow et al., 1993]. However, following neonatal castration, males tested as adults did not form partner preferences in response to centrally administered AVP. Neonatal treatment with testosterone restored the ability of castrated male prairie voles to respond to AVP in adulthood, in this case with the formation of a partner preference. Replacement of testosterone in adulthood did not restore partner preference formation in response to AVP in neonatally castrated males, suggesting once again that the postnatal period is a time when animals are especially sensitive to hormonal manipulations. Interestingly, in that study neonatal castration did not affect the distribution of AVP V1aR, as measured by autoradiography [Cushing et al., 2003]. This conclusion is also supported by the general absence of sex differences in either the OTR or AVP VlaR that have been reported in several studies. The lack of an effect of neonatal castration on the $\mathrm{VlaR}$ is in contrast to the significant and sexually dimorphic effects of neonatal manipulations of OT on the V1aR [Bales et al., 2007b]. These findings suggest the hypothesis that changes in peptides in early life, and especially manipulations of OT, may be more relevant than changes in gonadal steroids in regulating later peptide receptor distribution.

\section{Sex Differences}

The consequences of developmental manipulations of OT are often sexually dimorphic, relying on different neural substrates in males and females [Carter, 2007]. One possible reason for the differences between the sexes may be because in males the developmental effects of OT or OTA are mediated, at least in part, through differential ef- fects on AVP [Yamamoto et al., 2004] and/or the V1aR [Bales et al., 2007b]. In both sexes manipulations of the OT system by either OT $(3 \mu \mathrm{g})$ or OTA $(0.3 \mu \mathrm{g})$ did not have a significant effect on the OTR or dopamine receptor (D2) as measured by autoradiography [Bales et al., 2007b].

Because parental care behavior was a major dependent variable in these studies, we analyzed the impact of factors, including peptide administration and stressful experiences, on adult parental behavior. Adult male parental behavior was only eliminated by high dosages of both OTA and a vasopressin V1aR antagonist [Bales et al., 2004]. In another study in adults, prairie voles were either stressed (by a 3-min swim) or not stressed, and then tested with infants. Components of adult male alloparental responses towards infants were increased by the prior swim, while female alloparental behaviors were unaffected [Bales et al., 2006]. It is likely that AVP, as well as OT, was released during these stressors. Sex differences in central AVP and sex differences in the physiology of parental behavior [Bales et al., 2004; Wang et al., 1998], and specifically the reliance of males on AVP, may help to explain the capacity of stressful experiences to enhance male alloparental behavior.

Estrogen, with the well-documented capacity to increase the synthesis and possibly release of OT, also may help create sex differences. For example, by upregulating OT, estrogen might protect females against some of the factors capable of affecting male social behaviors. In contrast, the relatively larger role of AVP in certain aspects of male sociality and emotion regulation, and the concurrent vulnerability of the AVP system to neonatal hormonal manipulations could be important in understanding male vulnerabilities to developmental disorders such as autism.

\section{Developmental Signaling Consequences of Neuropeptides}

Maternal OT can act as a signaling mechanism between the mother and fetus. Based on studies in rats, maternal OT, released during birth, also triggers a transient switch in GABA signaling in the fetal brain from excitatory to inhibitory. In vivo administration of an OTA before delivery prevented this switch of GABA activity in fetal neurons, and aggravated the severity of anoxic episodes. Thus it appears that maternal OT inhibits fetal neurons and increases their resistance to hypoxic insult [Khazipov et al., 2008; Tyzio et al., 2006]. In addition, the birth-related surge in $\mathrm{OT}$ also helps to regulate the synchronization of the fe- 
tal hippocampal neurons, possibly allowing the transition from prenatal to postnatal life [Crepel et al., 2007]. Such changes would be expected to have consequences for both emotional and cognitive functions.

\section{Mechanisms of Long-Lasting Effects of Early Experience}

The OTR is susceptible to epigenetic regulation, for example, by silencing genes via methylation [Kimura et al., 2003; Szyf et al., 2005]. The capacity of genes that code for receptors to be silenced or otherwise modified in early life may be particularly relevant to understanding the long-lasting consequences of early experiences, whether originating as behavioral or as hormonal experiences. Effects on early experiences, including prenatal stress and postnatal social interactions, are mediated at least in part by plasticity in peptide receptors, as well as in the neurons that synthesize peptides including OT [Theodosis, 2002].

In rats prenatal stress can reduce expression of the OTR in later life [Champagne and Meaney, 2006]. There are also postnatal effects of early parental stimulation on binding to the OTR and V1aR, and these effects are sexually dimorphic [Champagne et al., 2001; Francis et al., 2002]. In rats, early experience affected the OTRs more in females and the V1aRs in males. In mice, males are more affected than females by genetic disruption of the V1aR [Bielsky et al., 2005; Lim et al., 2004b].

Our work with prairie voles suggests that during critical periods in development, social experiences or manipulations of OT or AVP may influence the expression of these same peptides, as well as their receptors, with life-long behavioral consequences. However, it is not a simple matter to untangle differential functions of OT and AVP, especially using available pharmacological tools. OT and AVP can bind to each other's receptors [Barberis and Tribollet, 1996]. In addition, the OT antagonist widely used in behavioral studies is not totally selective for the OTR and also affects the V1aR.

\section{Translational Implications of Perinatal Manipulations of OT}

Of particular concern and largely unstudied in humans are the possible consequences of exposure to exogenous peptides, including OT, in the perinatal period. The use of synthetic OT (pitocin) has grown in preva- lence as a method for inducing or augmenting labor. Prematurity also continues to be a major medical problem and treatments attempting to delay labor hold the potential to affect the fetus. OTAs, such as atosiban (currently not approved in the USA, but available in 43 other countries), have been used to delay or prevent premature labor [Husslein, 2002]. Other OTAs are being developed as methods for delaying parturition. However, the consequences for human brain and behavior of early OT manipulations, including exogenous OT, or of the use of OTAs remain largely unknown.

The possible effects of early experience or hormonal manipulations also have not been systematically studied in human development. The neural systems that are altered by neonatal peptide manipulations in prairie voles are evolutionarily ancient and have broad behavioral and physiological actions. Our studies suggest that these systems may be accessible to change and thus vulnerable during development to neural changes that could have long-lasting consequences. Results from our studies suggest the need for a deeper understanding of the mechanisms through which manipulations in endogenous or exogenous peptides might affect neuroanatomy, physiology and behavior. For example, manipulations in OT could have long-lasting consequences for behavioral endophenotypes, including sociality and reactivity to stressors, that are core to personality types and in extreme cases to several psychiatric disorders, including autism [Carter, 2007], anxiety and depression [Carter and Altemus, 2004] and possibly schizophrenia. Functional sex differences in neuropeptides, including AVP and possibly OT, may have particular significance for understanding sexually biased disorders [Carter, 2007]. Early manipulations of OT also can program various aspects of the body's management of stressful experiences, including measures of behavior, brain activity and chemistry, stress-related hormones and even receptors for stress hormones in the heart [Pournajafi-Nazarloo et al., 2007b]. A deeper understanding of the capacity of medical interventions or differential child rearing practices is greatly needed.

\section{Acknowledgements}

We are grateful for support from the National Institutes of Health - HD38490 (C.S.C.), MH073022 (C.S.C., K.L.B.), HD08702 (K.L.B.), MH018882 (E.M.B.), MH072109 (E.M.B.), National Science Foundation - 0437532 (K.L.B.) and the Institute for Research on Unlimited Love. 


\section{References}

Bales KL, Carter CS (2003a): Sex differences and developmental effects of oxytocin on aggression and social behavior in prairie voles $(\mathrm{Mi}$ crotus ochrogaster). Horm Behav 44:178184.

Bales KL, Carter CS (2003b): Developmental exposure to oxytocin facilitates partner preferences in male prairie voles (Microtus ochrogaster). Behav Neurosci 117:854-859.

-Bales KL, Kim AJ, Lewis-Reese AD, Carter CS (2004): Both oxytocin and vasopressin may influence alloparental behavior in male prairie voles. Horm Behav 45:354-361.

Bales KL, Kramer KM, Lewis-Reese AD, Carter CS (2006): Effects of stress on parental care are sexually dimorphic in prairie voles. Physiol Behav 87:424-429.

Bales KL, Lewis-Reese AD, Pfeifer LA, Kramer KM, Carter CS (2007a): Early experience affects the traits of monogamy in a sexually dimorphic manner. Dev Psychobiol 49:335342 .

-Bales KL, Plotsky PM, Young LJ, Lim MM, Grotte ND, Ferrer E, Carter CS (2007b): Neonatal oxytocin manipulations have longlasting, sexually dimorphic effects on vasopressin receptors. Neuroscience 144:38-45.

Barberis C, Tribollet E (1996): Vasopressin and oxytocin receptors in the central nervous system. Crit Rev Neurobiol 10:119-154.

-Bester-Meredith JK, Marler CA (2003): Vasopressin and the transmission of paternal behavior across generations in mated, crossfostered Peromyscus mice. Behav Neurosci 117:455-463.

Bielsky IF, Hu SB, Young LJ (2005): Sexual dimorphism in the vasopressin system: lack of an altered behavioral phenotype in female V1a receptor knockout mice. Behav Brain Res 164:132-136.

Caldwell HK, Wersinger SR, Young WS (2008): The role of vasopressin $1 \mathrm{~b}$ receptor in aggression and other social behaviors. Prog Brain Res 170:65-72.

-Carter CS (1998): Neuroendocrine perspectives on social attachment and love. Psychoneuroendocrinology 23:779-818.

Carter CS (2003): Developmental consequences of oxytocin. Physiol Behav 79:383-397.

-Carter CS (2007): Sex differences in oxytocin and vasopressin: implications for autism spectrum disorders? Behav Brain Res 176: $170-186$.

Carter CS, Altemus M (2004): Oxytocin, vasopressin, and depression; in den Boer JA, George MS, ter Horst GJ (eds): Current and Future Developments in Psychopharmacology. Amsterdam, Benecke, pp 201-216.

Carter, Boone EM, Bales KL (2008): Early experience and the developmental programming of oxytocin and vasopressin; in Bridges RS (ed): Neurobiology of the Parental Brain. San Diego, Elsevier, pp 417-433.
Carter CS, DeVries AC, Getz LL (1995): Physiological substrates of mammalian monogamy: the prairie vole model. Neurosci Biobehav Rev 19:303-314

-Champagne F, Diorio J, Sharma S, Meaney MJ (2001): Naturally occurring variations in maternal behavior in the rat are associated with differences in estrogen-inducible central oxytocin receptors. Proc Natl Acad Sci USA 98:12736-12741.

Champagne FA, Meaney MJ (2006): Stress during gestation alters postpartum maternal care and the development of the offspring in a rodent model. Biol Psychiatr 59:12271235.

Cho MM, DeVries AC, Williams JR, Carter CS (1999): The effects of oxytocin and vasopressin on partner preferences in male and female prairie voles (Microtus ochrogaster). Behav Neurosci 113:1071-1079.

Choleris E, Devidze N, Kavaliers M, Pfaff D (2008): Steroidal/neuropeptide interactions in hypothalamus and amygdala related to social anxiety. Prog Brain Res 170:291-303.

Crepel V, Aronov D, Jorquera I, Represa A, BenAri Y, Cossart R (2007): A parturition-associated nonsynaptic coherent activity pattern in the developing hippocampus. Neuron 54: $105-120$.

Cushing BS, Kramer KM (2005): Mechanisms underlying epigenetic effects of early social experience: the role of neuropeptides and steroids. Neurosci Biobehav Rev 29:10851105.

Cushing BS, Okorie U, Young LJ (2003): The effects of neonatal castration on the subsequent behavioural response to centrally administered arginine vasopressin and the expression of $\mathrm{V}$-1a receptors in adult male prairie voles. J Neuroendocrinol 15:10211026.

De Vries, Simerly RB (2002): Anatomy, development, and function of sexually dimorphic neural circuits in the mammalian brain; in Pfaff DW (ed): Hormones, Brain, and Behavior. San Diego, Academic Press, vol 4, pp 137-192.

-Engelmann M, Landgraf R, Wotjak CT (2004): The hypothalamic-neurohypophysial system regulates the hypothalamic-pituitary adrenal axis under stress: an old concept revisited. Front Neuroendocrinol 25:132-149.

-Francis DD, Young LJ, Meaney MJ, Insel TR (2002): Naturally occurring differences in maternal care are associated with the expression of oxytocin and vasopressin (Vla) receptors: gender differences. J Neuroendocrinol 14:349-353.

Getz LL, Carter CS (1996): Prairie vole partner ships. Am Scient 84:56-62.
Gimpl G, Fahrenholz F (2001): The oxytocin receptor system: structure, function, and regulation. Physiol Rev 81:629-683.

Glynn LM, Davis EP, Schetter CD, Chicz-Demet A, Hobel CJ, Sandman CJ (2007): Postnatal maternal cortisol levels predict temperament in healthy breastfed infants. Early $\mathrm{Hu}-$ man Devel 83:675-681.

-Grosvenor CE, Picciano MT, Baumrucker CR (1993): Hormones and growth factors in milk. Endocr Rev 14:710-728.

Hammock EA, Young LJ (2005): Microsatellite instability generates diversity in brain and sociobehavioral traits. Science 308:16301634

Husslein P (2002): Development and clinical experience with the new evidence-based tocolytic atosiban. Acta Obst Gynecol Scand 81: 633-641.

-Insel TR, Shapiro LE (1992): Oxytocin receptor distribution reflects social organization in monogamous and polygamous voles. PNAS 89:5981-5985.

Khazipov R, Tyzio R, Ben-Ari Y (2008): Effects of oxytocin on GABA signalling in the fetal brain during delivery. Prog Brain Res 170: 243-254.

Kimura T, Saji F, Nishimori K, Ogita K, Nakamura H, Koyama M, Murata Y (2003): Molecular regulation of the oxytocin receptor in peripheral organs. J Mol Endocrinol 30:109115.

Kramer KM, Yoshida S, Papademitriou E, Cushing BS (2007): The organizational effects of oxytocin on the central expression of estrogen receptor alpha and oxytocin in adulthood. BMC Neurosci 8:71.

Landgraf R, Neumann ID (2004): Vasopressin and oxytocin release within the brain: a dynamic concept of multiple and variable modes of neuropeptide communication. Front Neuroendocrinol 25:150-176.

Leake RD, Weitzman RE, Fisher DA (1981): Oxytocin concentrations during the neonatal period. Biol Neonate 39:127-131.

Lim MM, Hammock EA, Young LJ (2004a): The role of vasopressin in the genetic and neural regulation of monogamy. J Neuroendocrinol $16: 325-332$

Lim MM, Hammock EAD, Young LJ (2004b): The role of vasopressin in the genetic and neural regulation of monogamy. J Neuroendocrinol 16:325-332.

Ophir AG, Wolff JO, Phelps SM (2008): Variation in neural V1aR predicts sexual fidelity and space use among male prairie voles in semi-natural settings. Proc Natl Acad Sci USA 105:1249-1254.

- Phelps SM, Young LJ (2003): Extraordinary diversity in vasopressin (V1a) receptor distributions among wild prairie voles (Microtus ochrogaster): patterns of variation and covariation. J Comp Neurol 466:564-576. 
Porges SW (1998): Love: an emergent property of the mammalian autonomic nervous system. Psychoneuroendocrinology 23:837-861.

- Pournajafi-Nazarloo H, Carr MS, Papademetriou E, Schmidt JV, Cushing BS (2007a): Oxytocin increases ERalpha mRNA expression in the hypothalamus and hippocampus of neonatal female voles. Neuropeptides 41:3944.

- Pournajafi-Nazarloo H, Perry A, Papademetriou E, Parloo L, Carter CS (2007b): Neonatal oxytoin treatment modulates oxytocin receptor, atrial natriuretic peptide, nitric oxide synthase, and estrogen receptor mRNA expression in rat heart. Peptides 28:1170-1177.

Stribley JM, Carter CS (1999): Developmental exposure to vasopressin increases aggression in adult prairie voles. Proc Natl Acad Sci USA 96:12601-12604.

-Szyf M, Weaver ICG, Champagne FA, Diorio J, Meaney MJ (2005): Maternal programming of steroid receptor expression and phenotype through DNA methylation in the rat. Front Neuroendocrinol 26:139-162.
Theodosis DT (2002): Oxytocin-secreting neurons: a physiological model of morphological neuronal and glial plasticity in the adult hypothalamus. Front Neuroendocrinol 23: 101-135.

Tyzio R, Cossart R, Khalilov I, Minlebaev M, Hubner CA, Represa A, Ben-Ari Y, Khazipov R (2006): Maternal oxytocin triggers a transient inhibitory switch in GABA signaling in the fetal brain during delivery. Science 314: 1788-1792.

Vivani D, Stoop R (2008): Opposite effects of oxytocin and vasopressin on the emotional expression of the fear response. Prog Brain Res 170:207-218.

Wang ZX, Young LJ, De Vries GJ, Insel TR (1998) Voles and vasopressin: a review of molecular, cellular, and behavioral studies of pair bonding and paternal behaviors. Prog Brain Res 119:483-499.

Weiser MJ, Foradori CD, Handa RJ (2008): Estrogen receptor beta in the brain: from form to function. Brain Res Rev 57:309-320.
Williams JR, Insel TR, Harbaugh CR, Carter CS (1994): Oxytocin centrally administered facilitates formation of a partner preference in female prairie voles (Microtus ochrogaster). J Neuroendocrinol 6:247-250.

Winslow JT, Hastings N, Carter CS, Harbaugh CR, Insel TR (1993): A role for central vasopressin in pair bonding in monogamous prairie voles. Nature 365:545-548.

Witt DM, Carter CS, Insel TR (1991): Oxytocin receptor binding in female prairie voles: endogenous and exogenous estradiol stimulation. J Neuroendocrinol 3:155-161.

Yamamoto Y, Carter CS, Cushing BS (2006): Neonatal manipulation of oxytocin affects expression of estrogen receptor alpha. Neuroscience 137:157-164.

Yamamoto Y, Cushing BS, Kramer KM, Epperson PD, Hoffman GE, Carter CS (2004): Neonatal manipulations of oxytocin alter expression of oxytocin and vasopressin immunoreactive cells in the paraventricular nucleus of the hypothalamus in a gender specific manner. Neuroscience 125:947-955.

>Young LJ, Murphy Young AZ, Hammock EA (2005): Anatomy and neurochemistry of the pair bond. J Comp Neurol 493:51-57. 